Резюме

Суржинский М.И. Легитимность государственных органов, принимающих участие в решении вопросов гражданства (на примере Украины).

Рассмотрены сущность и природа легитимности государственных органов, принимающих участие в решении вопросов гражданства. Исследованы различия и соотношения понятий легитимности, легальности, легитимации государственных органов, принимающих участие в решении вопросов гражданства, в теоретико-правовой и конституционной плоскости.

Ключевые слова: государственные органы, которые принимают участие в решении вопросов гражданства, легитимность, легальность, легитимация государственных органов.

\title{
Summary
}

Maksym Surzhynskyi. Legitimacy of State Bodies involved in Citizenship Issues (Ukraine).

In the extremely difficult conditions of today, the problems of citizenship for Ukraine have become extremely relevant, becoming one of the factors affecting the state of ensuring its national security. This includes the problem of understanding the legitimacy of the state bodies involved in addressing citizenship issues.

Legitimacy and legality are the main features that characterize the state bodies involved in addressing citizenship issues. However, legitimacy is not synonymous with legality.

The legality of state bodies involved in resolving citizenship issues is purely legal in nature and expresses the formal conformity of their creation and operation of law, that is, legal legitimacy.

The legitimacy of state bodies involved in citizenship matters means that they are supported by society.

Legitimacy is derived from the process of legitimation, after which the state bodies involved in resolving citizenship issues acquire the status of legitimacy.

According to the Law of Ukraine "On Citizenship of Ukraine" of January 18, 2001, the state bodies involved in the decision of citizenship include: President of Ukraine, Commission under the President of Ukraine on Citizenship, the central executive body implementing state policy in citizenship and its subordinate bodies, the Ministry of Foreign Affairs of Ukraine, diplomatic missions and consular posts of Ukraine.

The current legislation on citizenship of Ukraine not only legalizes the system of state bodies involved in solving citizenship issues, but also legitimizes their actions.

Key words: state bodies involved in solving citizenship issues, legitimacy, legality, legitimation of state bodies.

DOI: 10.36695/2219-5521.1.2020.23

УдК 342.8

\section{B.B. TAPOEBA}

Влада Владимировна Тароева, кандидат юридических наук, доцент Национального университета «Одесская юридическая академия»*

ORCID: 0000-0002-1549-8994

\section{ИЗБИРАТЕЛЬНАЯ ВЛАСТЬ В СОВРЕМЕННОЙ УКРАИНЕ}

Постановка проблемы. Для современных государств принцип разделения властей рассматривается в качестве определяющего в организации государственного механизма. Ряд исследователей обосновывают необходимость формирования новых ветвей власти и модификацию традиционных. В частности, утверждается существование избирательной ветви власти. Развитие избирательной ветви власти предполагает, что существуют такие органы государства, которые осуществляют избирательную деятельность и не должны быть подчинены какой-то другой ветви власти, поскольку каждая ветвь государственной власти связана с осуществлением определенной функции. При этом система органов избирательной ветви власти является иерархической. Деятельность системы органов избирательной ветви власти имеет общегосударственное, а не ведомственное назначение.

Анализ последних исследований и публикаций. Дальнейшее развитие украинского государства определило значительный интерес исследователей к разным разработкам относительно проблемы разделения властей. Здесь можно назвать таких ученных, как: М. Баймуратов, В. Копейчиков, Ю. Оборотов, В. Погорилко, В. Шаповал, М. Орио, Ю. Веденеев, А. Автономов, В. Чиркин, С. Станских, Н. Колпаков и др.

Формулировка цели статьи. Цель исследования - в обосновании концептуальных основ самостоятельности избирательной ветви власти и ее институтов, а также формулирование предложений относительно институализации избирательной ветви власти в контексте реализации принципа разделение власти в современной Украине.

Изложение основного материала. Идеи правового государства и разделение властей в Украине утверждается с принятием Верховной Радой Украины 16 июля 1990 г. Декларации о государственном суверенитете Украины ${ }^{1}$. Именно в этом документе впервые был провозглашен принцип разделения государственной власти на законодательную, исполнительную и судебную как основу государственного строя Украины.

(C) В.В. Тароева, 2020

*Vlada Taroyeva, Ph.D. in Law, Associate Professor of the National University "Odesa Law Academy" 
Первоначальное внимание специалистов к триаде разделение власти: законодательную, судебную и исполнительную затем переместилось на контрольную власть, а позднее - на избирательную власть. Конституционная доктрина некоторых стран Латинской Америки (конституции Никарагуа 1987 г., Колумбии 1991 г. и др.) исходит из существования четырех ветвей государственной власти, среди которых дополнительно названа избирательная власть. Заметим, что Федеральный Закон Австрии 1992 г. «О выборах в Национальный Совет» также выделяет избирательную власть. Особенно актуальным и дискуссионным, на наш взгляд, остается вопрос об избирательной власти, которая и является предметом данного исследования.

Среди публикаций по теме избирательной власти можно назвать статью Ю.А. Веденеева $(1995 \text { г. })^{2}$, фундаментальную монографию А.С. Автономова «Избирательная власть» $(2002 \text { г. })^{3}$. Довольно часто избирательная власть упоминается и выделяется в рамках отдельных исследований, посвященных разделению властей и избирательным комиссиям.

Можно констатировать, что по мере увеличения и развития государственных функций и расширения сфер компетенции происходит переосмысление и выделение новых ветвей государственной власти, отвечая интересам развития общества и человека. Не стала исключением такая ветвь государственной власти, как избирательная.

Разные авторы в понятие избирательной власти вкладывают разный смысл:

- власть избирателей (М. Ориу, Ю.А. Веденеев, В.Е. Чиркин), власть избирательного корпуса и избирательных комиссий (Н.В. Колпаков);

- власть избирательных комиссий (А.С. Автономов, С.Н. Станских).

Используя систему признаков ветви государственной власти, предложенную В.Е. Чиркиным, можно констатировать, что избирательная власть является ветвью государственной власти.

В первую очередь избирательная власть институализировалась, поскольку существуют такие государственные органы, которые принято называть избирательными. По мнению Дж. Шабир Чима, «избирательное администрирование» является относительно новой сферой изучения и практики. В последние десятилетия наблюдается тенденция к возрастанию роли избирательного администрирования как института демократии. Реформаторская деятельность в этой сфере привела к созданию избирательной власти в форме избирательных комиссий, которые являются постоянными и независимыми от исполнительной власти органами, включающими представителей политических партий и укомплектованные профессиональными гражданскими служащими. В 52 \% всех государств существуют независимые избирательные комиссии. В 29 \% правительства проводят выборы под контролем избирательной власти. И только в 19 \% государств выборы организует исключительно исполнительная власть.

Пауль Грахам считает, что «избирательное законодательство может включать положения, устанавливающая избирательную власть и ее функции». При этом он подчеркивает, что «различные избирательные системы предъявляют различные требования к избирательным властям».

В демократических государствах органы, организующие выборы, формируют институты государственной власти и местного самоуправления, причем такие институты, которые обладают наивысшими полномочиями на соответствующем уровне. В результате выборов власть, принадлежащая народу, передается его представителям. А организуют процесс волеизъявления народа, подсчитывают поданные голоса, подводят итоги выборов и объявляют об их результатах избирательные комиссии. При проведении выборов многое зависит от эффективности работы избирательных комиссий, от слаженности функционирования всех звеньев системы избирательных органов, прозрачности избирательных процедур, открытости избирательных органов во взаимодействии с негосударственными организациями и средствами массовой информации. Относительно роли избирательной функции подчеркивается, что в демократическом государстве, в котором господствует право, которое опирается на систему гражданских свобод, определяющих действия этого государства, редко какая иная функция, если она осуществляется не должным образом или в недостаточной мере, может нанести такой же значительный ущерб, как организация избирательного процесса.

Заметим, что при отсутствии демократии, но при стремлении сохранить видимость выборов, избирательным органом уделяется особое внимание с тем, чтобы они обеспечили нужные руководителям государства результаты голосования. В то же время, при демократическом режиме избирательные органы обеспечивают формирование выборных государственных и муниципальных органов, без которых в современных условиях невозможно осуществить народовластие. Таким образом, избирательная власть предполагает наличие особых государственных институтов, и осуществляемая ими деятельность составляет сферу исследований как юристов, так и политологов.

Во многих странах законодательство не устанавливает в системе разделения власти избирательной ее ветви. Тем не менее, ряд юристов - теоретиков и практиков, считают избирательную власть фактически включенной в систему разделения властей. Так, Председатель Избирательного суда Уругвая полагает, что данный суд, являющийся высшим избирательным органом, представляет самостоятельную ветвь власти, поскольку закрепляет такой статус этого суда, который вполне позволяет по всем признаком отнести его к отдельной ветви власти. Он высказывается в пользу ее официального оформления, поскольку ни к какой иной, кроме как избирательной ветви, власти нельзя отнести орган, организующий выборы, даже несмотря на то, что этот орган наделен дополнительно судебными полномочиями. Бывший член Национального судебного совета по выборам Перу Вальдивия Кано полагает, что несмотря на то, что Конституция Перу указывает только три ветви власти - законодательную, исполнительную и судебную, Национальный судебный совет по выборам представляет собой самостоятельную ветвь государственной власти. Он пишет, что указанный Совет «обладает всеми атрибутами, которые конституционная доктрина считает необходимым иметь для обретения качества ветви власти в государстве». Заметим, что вопрос о принадлежности избирательного 
органа к той или иной ветви власти привлек внимания в первую очередь практиков, поскольку принцип разделения властей в государстве представляет собой основу построения всего механизма реализации государственной власти.

В теории разделение властей наряду с законодательной, исполнительной и судебной властью в ряде государств выделяются такие ветви власти, как избирательная и контрольная. В современных государствах все шире внедряются в практику различные формы прямой демократии, такие как выборы или референдум, чтобы они были организованы надлежащим образом. Для достижения этой цели необходимо, чтобы выборы и референдум организовывались специализированными органами, независимыми в административном отношении от других органов государства, и подчинялись только закону.

В современной Украине возможно формирование избирательной власти как самостоятельной и независимой ветви государственной власти. Если анализировать ст. 1 Конституции Украины, можно утверждать, что Украина стремится к тому, чтобы обеспечить трансформацию государственной власти в пользу носителя суверенитета и единственного источника государственной власти, которым в Украине является народ. Поэтому избирательная ветвь власти должна стать закономерным и ожидаемым в развитии идеи разделения властей в Украине.

Избирательная власть, является частью институциональной основы государства, она тесно связана с конституционной, партийной и политической системой, и результат ее действия будет разным в политикоправовых и партийных реалиях. Формировать избирательную власть необходимо с учетом национальных конституционных и политических особенностей ${ }^{4}$.

Непосредственное народовластие может осуществляться как на президентских и парламентских выборах, всеукраинском референдуме, так и на местном уровне.

Принцип народного суверенитета как фундаментальный принцип демократического правового государства закрепляется в ст. 5 Конституции Украины. Основной Закон провозглашает, что права определять и изменять конституционный строй в Украине принадлежит исключительно народу. При этом предусматривается непосредственное, а также через органы государственной власти, осуществление власти народом.

Государство через избирательную власть получает право управлять от имени народа, защищать его интересы, вступать в международные отношения, регулировать общественные отношения, что обязывает государство создавать условия для функционирования институтов политической системы и гражданского общества.

По мнению А.И. Кормича, современная демократия должна обязательно отвечать принципам легитимности, плюрализма и верховенства права. Они должны охватывать всю сферу государственной власти и управления, функционирования институтов гражданского общества, взаимодействия государства и общества, распространяясь на нормативные, организационные и процессуальные вопросы относительно этих сфер. При этом посредством избирательной власти есть возможность согласования индивидуальных и общественных интересов, в разных сферах, можно избегать конфликты между проявлением воли индивида и воли общества ${ }^{5}$.

В Украине специальными органами избирательной власти выступают избирательные комиссии во главе с Центральной избирательной комиссией. Здесь мы сталкиваемся с проблемой определения природы избирательных комиссий, а, следовательно, институализации избирательной власти в Украине.

Центральная избирательная комиссия Украины является постоянно действующим государственным коллегиальным органом, который наделен полномочиями по организации подготовки и проведения выборов в органы государственной власти. Главной задачей ЦИК Украины является обеспечение реализации и защиты конституционных суверенных прав граждан на выборы власти, участие в референдумах, а также волеизъявление. Для исполнения своих обязанностей ЦИК наделена правами и полномочиями, которые позволяют задействовать в процессе избирательной компании государственные органы всех уровней. ЦИК является независимым и самостоятельным органом, финансируется исключительно из бюджета.

Правовой статус Центральной избирательной комиссии определяется Конституцией Украины, Законом Украины «О Центральной избирательной комиссии» и другими законами Украины. Центральная избирательная Комиссия возглавляет систему избирательных комиссий, которые организовывают подготовку и проведения выборов депутатов, и является комиссией высшего уровня в отношении всех окружных и территориальных избирательных комиссий, предусмотренных Законом ${ }^{6}$.

Исследуя президентские выборы 2019 г., а также выборы в Верховную Раду Украины, можно утверждать, что Центральная Избирательная Комиссия как институт избирательной власти сыграла решающую роль в проведении независимых выборов.

В Украине с 1 января 2020 г. начал действовать Избирательный кодекс Украины, предусматривающий пропорциональную систему выборов с открытыми списками и гарантирующий гендерный баланс. Закон предусматривает, что избиратели на выборах будут голосовать не только за партию, но и за конкретного кандидата в списке партии. При формировании общегосударственного и региональных избирательных списков партия должна обеспечить присутствие в каждой пятерке каждого избирательного списка мужчин и женщин (не менее двух кандидатов каждого пола). В законе также оговаривается, что официальными наблюдателями на выборах не могут быть граждане или подданные государства, признанного Верховной Радой государством агрессором или государством-оккупантом.

Как следует из вышеизложенного, деятельность избирательных органов, органов референдума носит общегосударственный характер. Следовательно, этот признак переносится и на избирательную ветвь власти.

Среди признаков ветви государственной власти, которые присущи избирательной власти, такие:

1) избирательные органы формируются в особом порядке, исходя из функциональной направленности; 
2) имеют достаточную внутреннюю самостоятельность в процессе организации работы их системы;

3) им присущ особый порядок взаимодействия с институтами гражданского общества;

4) присутствует обособление выполняемых функций;

5) финансируется только из бюджета.

По мнению Н.В. Колпакова, «именно избирательная власть может претендовать на то, чтобы считаться верховной властью в демократическом государстве»7. Сложно согласиться с такой позицией, поскольку доминирование любой ветви власти над остальными противоречит потребностям современного государства, игнорирует универсальную систему сдержек и противовесов в отношении всех ветвей государственной власти.

Вместе с тем, анализируя избирательную власть, можно констатировать, что избирательная власть только тогда утверждается как ветвь государственной власти, когда она функционально независима от других ветвей государственной власти. Таким образом, характеристики самостоятельности и независимости неотъемлемые свойства избирательной власти.

Заметим, что в международной практике существуют различные «механизмы администрирования выборов», такие как правительственный, судебный, многопартийный и экспертные подходы, описанные А.А. Вешняковым ${ }^{8}$.

При этом общим требованиям к административным структурам, организующим выборы, является объективность, беспристрастность и независимость.

Данный подход существует и в международных избирательных стандартах.

Комитет по правам человека ООН закрепил, что «независимая избирательная власть должна создаваться для контроля над избирательным процессом и для гарантий проведения честных, справедливых выборов в соответствии с установленными законами»9.

Выводы. Таким образом, избирательная власть как ветвь государственной власти представляет собой полномочия по осуществлению подготовки и проведению выборов и референдумов, а также обеспечению, реализации и защите избирательных прав и права на участие в референдуме граждан определенного государства и систему избирательных органов разных уровней, реализующих эти полномочия.

В современном мире избирательная власть через избирательные органы во многих государствах институализировалась, а в некоторых и конституировалась, то есть получила легальное, конституционное закрепление.

Аналогичные процессы происходят в современной Украине. Создание теоретических основ избирательной власти с точки зрения общетеоретической юриспруденции и науки конституционного права позволит поставить вопрос о закреплении избирательной власти как ветви государственной власти в Конституции Украины.

${ }^{1}$ Рудич Ф.М. Політичні структури та процеси в сучасній Україні: Політичний аналіз. Київ: Наук. думка, 1995. 338 с.

2 Веденеев Ю.А. Избирательная власть: исторический контекст, политико-правовая сущность и механизм осуществления. Бюллетень Центральной избирательной комиссии РФ. 1995. № 2(28). С. 39-49.

3 Автономов А.С. Избирательная власть. Москва: Права человека, 2002. 88 с.

4 Осудчук К.О. Щодо нормативного закріплення виборчої влади в Україні. Прикарпатський юридичний вісник. 2015. C. $12-15$.

5 Кормич А.І. Сучасна демократія: диверсифікація форми та змісту. Актуальні грані загальнотеоретичної юриспрудениії: монографія / Ю.М. Оборотов; за ред. Ю.М. Оборотова. Одеса: Фенікс, 2012. 492 с.

${ }^{6}$ Совгіря О.В., Шукліна Н.Г. Конституційне право України. Повний курс. Київ: Юрінком Інтер, 2019. 500 с. С. 226.

${ }^{7}$ Колпаков Н.В. Теоретическая модель разделение властей на примере современной России. Юридическое образование и наука. 2001. № 2. С. 24-25.

${ }^{8}$ Избирательное право и избирательный процесс в Российской Федерации: учебник для вузов / отв. ред. А.В. Иванченко. Москва: Норма, 1999. С. 138.

${ }_{9}^{9}$ Станских С.Н. Избирательная власть как ветвь государственной власти: к постановке проблемы. Институты власти в конституционном праве. Теория разделения властей. 2004. № 1. С. 18.

\section{Резюме}

Тароєва В.В. Виборча влада в сучасній Україні.

У статті представлено, що виборча гілка державної влади поступово формується в самостійну галузь державної влади в Україні, в якій є особливі органи держави. Виборча влада вже $є$ складовою поділу влади в сучасній держави, як важлива гарантія верховенства права й умова демократичного функціонування державної влади. Виборча влада стає невід'ємним компонентом механізму поділу влади. Розвиток державності України актуалізує необхідність відповідного наукового забезпечення та інституалізації влади і правової регламентації її здійснення. комісія.

Ключові слова: державна влада, галузі державної влади, виборча влада, інститути виборчої влади, Центральна виборча

\section{Резюме}

Тароева В.В. Избирательная власть в современной Украине.

В статье представлено, что избирательная ветвь государственной власти постепенно формируется в самостоятельную ветвь государственной власти в Украине, в которой функционируют особые органы государства. Избирательная власть уже является составляющей разделения властей в современном государстве. Это - важная гарантия верховенства права и условия демократического функционирования государственной власти. Избирательная ветвь государственной власти становится неотъемлемым компонентом механизма разделения властей. Развитие государственности Украины актуализирует необходимость соответствующего научного обеспечения институализации власти и правовой регламентации ее осуществления. 
Ключевые слова: государственная власть, ветви государственной власти, избирательная власть, институты избирательной власти, Центральная избирательная комиссия.

\section{Summary}

Vlada Taroyeva. Electoral branch of power in modern Ukraine.

The article introduces that the electoral branch is gradually being formed into an independent branch of state power in Ukraine, in which special state authorities operate. The electoral branch is already a component of the separation of powers in a modern state, and this is an important guarantee of the rule of law and of the condition for the democratic functioning of state power. The electoral branch is becoming an integral component of the separation of powers mechanism. The development of Ukrainian statehood actualizes the need for appropriate scientific support for the institutionalization of power and legal regulation of its realization. The electoral branch as a branch of state power represents the powers to conduct preparing and holding elections and referenda, as well as to ensure, exercise and protect the voting rights and the right of citizens of a certain state to participate in a referendum, as well as the system of electoral bodies of different levels exercising these powers.

In Ukraine, electoral commissions led by the Central Electoral Commission (CEC) are special electoral authorities. Here we are faced with the problem of determining the nature of electoral commissions, and therefore the institutionalization of the electoral branch in Ukraine. The CEC of Ukraine is a permanent state collegial body vested with the power to organize preparing and holding elections to the public authorities. The main task of the CEC of Ukraine is to ensure the realization and protection of constitutional sovereign rights of citizens to elect authorities, to participate in referenda, as well as to express their will. In order to fulfill its responsibilities, the $\mathrm{CEC}$ is endowed with rights and powers allowing the involvement of public authorities of all levels in the electoral campaign process. The CEC is an independent and autonomous body, financed exclusively by the budget.

In the modern world, electoral branch has been institutionalized through the electoral authorities in many states, and in some of them it has been constitutionalized, that is, it has been enshrined in the legislation and in the constitution.

Similar processes are taking place in modern Ukraine. The creation of the theoretical foundations of the electoral branch from the viewpoint of general theoretical legal science and constitutional legal science will enable to raise the question of enshrining the electoral branch as a branch of state power in the Constitution of Ukraine.

Key words: state power, branches of state power, electoral branch, institutions of electoral branch, Central Electoral Commission.

DOI: 10.36695/2219-5521.1.2020.24

УДК $342.4(477)+336.1$

\section{А.М. ХУДИк}

Андрій Мирославович Худик, помічник судді управління з організаційного забезпечення Апеляційної палати Вищого антикорупційного суду*

ORCID: 0000-0003-3174-8428

\section{КОНСТИТУЦІЙНИЙ ПРИНЦИП ВСТАНОВЛЕННЯ ПОДАТКІВ І ЗБОРІВ ВИКЛЮЧНО ЗАКОНАМИ УКРАЇНИ}

Постановка проблеми. Конституція України закріпила право приватної власності як один із найважливіших елементів конституційного ладу. Саме цей принцип забезпечує приватним власникам можливість вільно використовувати належне їм майно, гарантує стабільність відносин власності, не допускає довільного позбавлення майна та непропорційності обмеження права приватної власності1. Водночас право власності, зокрема й приватної, не є абсолютним. Його здійснення має певні конституційні межі, встановлені, серед іншого, положеннями ч. 3 ст. 13, ч. 7 ст. 41 Основного Закону України, у яких зазначається, що власність зобов'язує і не повинна використовуватися на шкоду людині й суспільству, правам, свободам та гідності громадян, інтересам суспільства, погіршувати екологічну ситуацію і природні якості землі. Крім того, Конституція України, закріплюючи гарантії права приватної власності, зобов'язує кожного «сплачувати податки і збори в порядку і розмірах, встановлених законом»².

Вважаємо, що важливим аспектом у дослідженні проблеми конституціоналізації публічних фінансів в Україні $є$ юридична конструкція та зміст закріпленого в Конституції України фундаментального принципу правового регулювання податкової системи України - принципу встановлення податків і зборів виключно законами України, що і $є$ предметом розгляду у цій статті.

Аналіз останніх досліджень і публікацій. Правову природу та зміст конституційного принципу встановлення податків і зборів тільки законами України (з позиції конституційного права) досліджували такі українські та зарубіжні вчені: Н.С. Бондар, А.В. Бризгалін, Д.В. Віницький, Р.О. Гаврилюк, Г.А. Гаджієв, А.Н. Козирін, М.П. Кучерявенко, С.Г. Пепеляєв, А.А. Пилипенко, В.А. Соловйов, Є.В. Тарібо та інші.

Формулювання мети статті. Мета статті полягає у з'ясуванні правової природи та конституційних вимог до принципу встановлення податків і зборів виключно законами України.

Виклад основного матеріалу. Важливим конституційним принципом податкового права $\epsilon$ принцип встановлення податків і зборів «виключно законами України». Так, згідно з Конституцією України, податок може бути встановлений, змінений або скасований тільки законом. Це положення закріплено у двох статтях

(C) А.М. Худик, 2020

* Andriy Khudyk, Assistant judge Court of Appeal of the Supreme Anti-Corruption Court 